\title{
Association between multifocal soft contact lens decentration and visual performance
}

\section{Cathleen Fedtke' \\ Klaus Ehrmann ${ }^{1,2}$ \\ Varghese Thomas' \\ Ravi C Bakaraju ${ }^{1,2}$}

'The Brien Holden Vision Institute, Clinical Trial Research Centre, ${ }^{2} \mathrm{School}$ of Optometry and Vision Science, The University of New South Wales, Sydney, NSW, Australia
Correspondence: Ravi C Bakaraju The Brien Holden Vision Institute, Clinical Trial Research Centre, Level 5, North Wing, Rupert Myers Building, Gate 14, Barker Street, UNSW, Sydney, NSW 2052, Australia

Tel +6I 293857516

Fax +6I 29385740 I

Email r.bakaraju@brienholdenvision.org
This article was published in the following Dove Press journal:

Clinical Optometry

28 June 2016

Number of times this article has been viewed

Purpose: The aim of this study was to assess the association between decentration of several commercial multifocal soft contact lenses (MFCLs) and various objective and subjective visual performance variables in presbyopic and non-presbyopic participants.

Materials and methods: All presbyopic (age $>40$ years, near add $\geq+1.25 \mathrm{D}$ ) and non-presbyopic (age $\geq 18$ years, no near add requirements, spherical equivalent $\leq-0.50 \mathrm{D}$ ) participants were each fitted bilaterally with six and two MFCLs (test lens), respectively, and with one single vision lens (control lens). Lens decentration, ie, the $x$ - and $y$-differences between the contact lens and pupil centers, was objectively determined. Third-order aberrations were measured and compared. Visual performance (high- and low-contrast acuities and several subjective variables) was analyzed for any associations (Pearson's correlation, $r$ ) with MFCL decentration.

Results: A total of 17 presbyopic ( $55.1 \pm 6.9$ years) and eight non-presbyopic (31.0 \pm 3.3 years) participants completed the study. All lenses displayed a temporal-inferior decentration $(x=-$ $0.36 \pm 0.29 \mathrm{~mm}, y=-0.28 \pm 0.28 \mathrm{~mm}$, mean $\pm \mathrm{SD}$ ). Compared to the control, a significant inferior decentration was found for the Proclear ${ }^{\circledR}$ MFCL Near lens in both groups $\left(y_{\text {presbyopic }}=-0.26 \mathrm{~mm}\right.$, $y_{\text {non-presbyopic }}=-0.70 \mathrm{~mm}$ ) and for the Proclear ${ }^{\circledR}$ MFCL Distance lens in the non-presbyopic group $\left(y_{\text {non-presbyopic }}=-0.69 \mathrm{~mm}\right)$. In both groups, lens-induced vertical coma $(\mathrm{C}(3,-1))$ was, by at least tenfold, significantly more positive for the Proclear ${ }^{\circledR}$ MFCL Distance lens and significantly more negative for the Proclear ${ }^{\circledR}$ MFCL Near lens. In the presbyopic group, the correlation of total MFCL decentration with vision variables was weak $(r<|0.191|)$. Conversely, a moderate but significant correlation with total MFCL decentration was found in the non-presbyopic group for most of the vision variables, indicating a decrease in vision as decentration increased.

Conclusion: Certain MFCLs decentered more than others; the same lens designs also induced significant amounts of third-order aberrations. An association between MFCL decentration and seven out of nine vision variables was found in the non-presbyopic group, ie, the group where lenses were most decentered, which had larger pupils and lower levels of inherent third-order aberrations. Keywords: vision, multifocal contact lenses, decentration, higher-order aberrations

\section{Introduction}

With the increasing active lifestyles of older people, multifocal soft contact lenses (MFCLs) offer a practical alternate refractive correction when compared to traditional bi-/multifocal spectacle lenses or rigid gas permeable contact lenses. The globally increasing number of people requiring a presbyopic correction additionally reinforces the need for such an alternative correction method. Besides presbyopic refractive correction, the use of MFCLs has also been of increased interest in relation to controlling the progression of myopia. ${ }^{1,2}$ Such lenses permit the reduction in foveal or peripheral 
hyperopic retinal defocus, an intervention approach that has been suggested to counteract the stimulus for eye growth. ${ }^{3,4}$

When compared to single vision (SV) or multifocal spectacle lenses, vision with current MFCLs is often compromised since the optical design of MFCLs requires the simultaneous presentation of images through the limited area of the pupil. Ghosting and haloes are often the consequence of this simultaneous imaging principle. ${ }^{5}$ Several studies have assessed the visual performance of commercial MFCLs in a presbyopic group $^{6-9}$ and a non-presbyopic myopic group..$^{2,10,11}$ In general, the quality of vision with MFCLs primarily depends on the power distribution across the optic zone, ie, the lens design (power profile), ${ }^{12}$ the near add power, ${ }^{11}$ and the size of the pupil. $^{13}$

Differences in ocular and lens design parameters, ie, base curve (BC) and diameter, and material properties can affect the fit of MFCLs and thereby lens centration. It has been reported ${ }^{11,14}$ that some MFCLs (ie, Proclear ${ }^{\circledR}$ MFCLs; CooperVision, Pleasanton, CA, USA) decentered more than others and that vision with those lenses was also more reduced. Based on these observations, it has been suggested that decentration of MFCLs might impact vision. Empirical calculations have shown that contact lens (CL) decentration can affect retinal image quality and increase odd higherorder aberrations such as coma. ${ }^{15,16}$ Peyre et al ${ }^{10}$ measured higher-order aberrations with several commercially available MFCLs and found an increase in even and odd higher-order aberrations. Although they did not measure CL centration, they attributed this increase in odd higher-order aberrations to the decentration of the lenses relative to the pupil. ${ }^{10}$ Fernández-Sánchez et a ${ }^{17}$ designed special soft CLs with low, medium, and high values of coma and trefoil to assess the effect of third-order aberrations on vision. They found that only lenses with large values of $\sim 1 \mu \mathrm{m}$ of coma and trefoil significantly reduced visual performance. However, they did not investigate any subjective visual performance variables, which previously have been suggested to be more sensitive indicators for the assessment of vision with MFCLs. ${ }^{7,11}$

To our knowledge, no clinical studies have as yet assessed the association between decentration of commercial MFCLs and vision in a presbyopic or a non-presbyopic group. The objective of this study was therefore to measure the amount of CL decentration and the lens-induced third-order aberrations of commercially available MFCLs and to assess the association between decentration and high-contrast visual acuity (HCVA) and low-contrast visual acuity (LCVA) and several subjective visual performance variables in a presbyopic and a non-presbyopic group.

\section{Materials and methods}

\section{Study design}

This was a prospective, participant-masked, bilateral wear, crossover clinical trial conducted at the Brien Holden Vision Institute, Sydney, Australia. For the presbyopic group, criteria for inclusion were age $>40$ years and near add $\geq+1.25 \mathrm{D}$, and for the non-presbyopic group the age was $\geq 18$ years, without any near add requirements, and be myopic (spherical equivalent $\leq-0.50 \mathrm{D}$ ). Independent of the group, the additional inclusion criteria were vision correctable to at least $6 / 9$ or better in each eye with CLs and astigmatism $\leq-1.00 \mathrm{DC}$, as the study was aimed to use spherical MFCLs to correct for distance refractive error. Exclusion criteria included previous corneal refractive surgery, any other ocular conditions, and any contraindications to CL wear. The protocols and informed consent were reviewed and approved by an independent ethics committee (Bellberry Limited, Eastwood, SA, Australia), and the research followed the tenets of the Declaration of Helsinki. Following the screening for clinical trial suitability, informed consent was obtained from each participant before any clinical trial procedures were performed. Each participant had to attend a baseline visit and up to six lens assessment visits.

\section{Contact lenses}

At the first lens assessment visit, participants were dispensed bilaterally with the AirOptix Aqua ${ }^{\circledR}$ SV lens (Alcon Laboratories, Inc., Fort Worth, TX, USA), which served as a control. During the next lens assessment visits, up to six commercially available MFCLs (test lenses) were randomly tested on separate days with a minimum washout period of 1 day between visits. The details of all study lenses are shown in Table 1. While the presbyopic group was fitted with all six MFCL test lenses, only two MFCLs, ie, Proclear $^{\circledR}$ MFCL Distance and Near, were fitted to the non-presbyopic group, as those lenses would provide the greatest myopia control effect due to the greater plus area under the distance labeled power profile. ${ }^{12}$ All measurements were performed after allowing a minimum of 10 minutes for the lenses to settle. Lenses remained on eye until all procedures were complete. The duration of each lens assessment visit was $\sim 1$ hour.

\section{Procedures}

\section{Refraction}

At the baseline visit, the participant's ocular refraction was determined under high illumination conditions (557 \pm 11 lux at participant eye position). All non-presbyopic participants were fitted with medium add lenses (add $+2.00 \mathrm{D})$. For the 
Table I Description of CLs

\begin{tabular}{|c|c|c|c|c|c|c|}
\hline CLs & Lens design & Manufacturer & Material & Power (D) & Diameter $(\mathbf{m m})$ & BC $(\mathbf{m m})$ \\
\hline $\begin{array}{l}\text { AirOptix }{ }^{\circledR} \text { Aqua } \\
\text { Single Vision }\end{array}$ & SV (negative control) & $\begin{array}{l}\text { Alcon Laboratories, Inc. } \\
\text { (Fort Worth, TX, USA) }\end{array}$ & Lotrafilcon B & $+4.00 \mathrm{D}$ to $-10.00 \mathrm{D}$ & 14.2 & 8.6 \\
\hline $\begin{array}{l}\text { Proclear }{ }^{\circledR} \text { Multifocal } \\
\text { Near }\end{array}$ & $\begin{array}{l}\text { Center-near } \\
\text { multifocal }\end{array}$ & $\begin{array}{l}\text { CooperVision } \\
\text { (Pleasanton, CA, USA) }\end{array}$ & Omafilcon A & $\begin{array}{l}+4.00 \mathrm{D} \text { to }-10.00 \mathrm{D} \\
\text { low/high add }\end{array}$ & 14.4 & 8.7 \\
\hline $\begin{array}{l}\text { Proclear }^{\circledR} \text { Multifocal } \\
\text { Distance }\end{array}$ & $\begin{array}{l}\text { Center-distance } \\
\text { multifocal }\end{array}$ & $\begin{array}{l}\text { CooperVision } \\
\text { (Pleasanton, CA, USA) }\end{array}$ & Omafilcon A & $\begin{array}{l}+4.00 \mathrm{D} \text { to }-10.00 \mathrm{D} \\
\text { low/high add }\end{array}$ & 14.4 & 8.7 \\
\hline $\begin{array}{l}\text { CLARITI }^{\circledR} \text { I Day } \\
\text { Multifocal }\end{array}$ & $\begin{array}{l}\text { Center-near } \\
\text { multifocal }\end{array}$ & Sauflon (London, UK) & Filcon II multifocal & $\begin{array}{l}+5.00 \mathrm{D} \text { to }-6.00 \mathrm{low} / \\
\text { high add }\end{array}$ & 14.1 & 8.6 \\
\hline $\begin{array}{l}\text { AirOptix }{ }^{\circledR} \text { Aqua } \\
\text { Multifocal }\end{array}$ & $\begin{array}{l}\text { Center-near } \\
\text { multifocal }\end{array}$ & $\begin{array}{l}\text { Alcon Laboratories, Inc. } \\
\text { (Fort Worth, TX, USA) }\end{array}$ & Lotrafilcon B & $\begin{array}{l}+6.00 \mathrm{D} \text { to }-1.00 \mathrm{D} \\
\text { low } / \mathrm{med} / \mathrm{high} \text { add }\end{array}$ & 14.2 & 8.6 \\
\hline ACUVUE $^{\oplus}$ Bifocal & Concentric bifocal & $\begin{array}{l}\text { Johnson \& Johnson } \\
\text { (Jacksonville, FL, USA) }\end{array}$ & Etafilcon A & $\begin{array}{l}+6.00 \mathrm{D} \text { to }-9.00 \mathrm{D} \\
+1.50 /+2.50 \mathrm{D} \text { add }\end{array}$ & 14.2 & 8.5 \\
\hline PureVision ${ }^{\circledast}$ Multifocal & Center-near multifocal & $\begin{array}{l}\text { Bausch \& Lomb } \\
\text { Incorporated (Rochester, } \\
\text { NY, USA) }\end{array}$ & Balafilcon A & $\begin{array}{l}+6.00 \mathrm{D} \text { to }-10.00 \mathrm{D} \\
\text { low/high add }\end{array}$ & 14.0 & 8.6 \\
\hline
\end{tabular}

Abbreviations: $\mathrm{BC}$, base curve; $\mathrm{CLs}$, contact lenses; SV, single vision.

presbyopic participants, the near add was obtained by the minimum plus required to comfortably read an N4-sized paragraph on a near-reading chart presented at $40 \mathrm{~cm}$, which would be equivalent to a visual acuity of $0.08 \log$ MAR . Distance over refraction was determined by providing maximum plus with which the participant was deemed to have acceptable binocular vision when looking at the $6 / 6$ line on a computer-generated letter chart (Test Chart 2000 Pro; Thompson Software Solutions, Hertfordshire, UK) at $6 \mathrm{~m}$.

Based on the presbyopic participants' spectacle near add, as determined at the baseline visit, participants were divided into two fitting groups (Table 2). As the objective of this study was to assess CL decentration and vision separately for each lens design, some MFCLs were fitted contrary to the manufacturers' fitting guides. Specifically, while the Proclear ${ }^{\circledR}$ MFCL fitting guide recommends to fit the center-near design lens in the nondominant eye and the center-distance design lens in the fellow dominant eye, participants in the current study were fitted the same design in both eyes. Further, the manufacturers' fitting guides for PureVision ${ }^{\circledR}$ MFCL and AirOptix ${ }^{\circledR}$ MFCL suggest to fit low add designs if the spectacle add is $\leq+1.25 \mathrm{D}$. As there was only one participant enrolled with $+1.25 \mathrm{D}$ add, this participant was, for simplicity and logistics reasons, dispensed with a medium add AirOptix ${ }^{\circledR}$ MFCL and a high add PureVision ${ }^{\circledR}$ MFCL with an extra $-0.25 \mathrm{D}$ for distance as indicated in the PureVision fitting guide/instruction booklet.

\section{Vision assessment}

At each lens assessment visit, distance HCVA (100\%) and LCVA (10\%) were measured with a computerized logMAR letter chart (Test Chart 2000 Pro) at $6 \mathrm{~m}$ under high illumination
Table 2 Fitting groups for multifocal test lenses based on spectacle add of presbyopic participants

\begin{tabular}{|c|c|c|}
\hline CLs & $\begin{array}{l}\text { Spectacle add } \\
+ \text { I.25 D and } \\
+ \text { I.50 D }\end{array}$ & $\begin{array}{l}\text { Spectacle add } \\
\geq+1.75 \mathrm{D}\end{array}$ \\
\hline AirOptix ${ }^{\circledR}$ Aqua Single Vision & $\begin{array}{l}\text { N/A (negative } \\
\text { control) }\end{array}$ & $\begin{array}{l}\text { N/A (negative } \\
\text { control) }\end{array}$ \\
\hline AirOptix ${ }^{\circledast}$ Aqua MFCL & Med add & High add \\
\hline Proclear $^{\circledR}$ MFCL Distance & +1.50 add & +2.50 add \\
\hline Proclear $^{\circledR}$ MFCL Near & +1.50 add & +2.50 add \\
\hline PureVision ${ }^{\circledR}$ MFCL & High add & High add \\
\hline ACUVUE $^{\circledR}$ Bifocal & +1.50 add & +2.50 add \\
\hline CLARITI $^{\circledR}$ I Day MFCL & Low add & High add \\
\hline
\end{tabular}

Abbreviations: CLs, contact lenses; N/A, not applicable; MFCL, multifocal soft contact lens.

conditions ( $557 \pm 11$ lux at participant eye position). After 1 hour of lens wear, participants completed a computer-based questionnaire, rating on a numerical scale the performance of each study lens (ie, monocularly). This scale ranged from 1 to 10 , where 1 indicates poorest performance and 10 indicates best performance. The resolution of the rating scale was \pm 1 unit. The questions included ratings on vision clarity at distance, intermediate and near, vision immediately after a blink, ghosting at distance and near, and overall vision satisfaction. It should be noted that a study by Tilia et $\mathrm{al}^{18}$ used a similar numerical rating scale of 1-10 for the assessment of subjective comfort variables. Although the resolution of their rating scale was 0.1 increments, their results suggest that a group mean difference over 0.5 would represent a perceivable difference.

\section{CL centration}

Using a Nikon Photo Slit Lamp (Nikon FS-3V; Nikon Corporation, Tokyo, Japan) that facilitated good alignment, CL centration was objectively determined by photographing the 
participant's anterior eye with the edge of the CL in focus (Figure 1A). The photograph was taken with the participant positioned in primary gaze and a few seconds after a blink, to ensure that the CL had stabilized, ie, no more movement.

The images were then uploaded into a dedicated customwritten MATLAB ${ }^{\circledR}$ (MathWorks, Inc. Natick, MA, USA) image analysis program, which was used to determine the difference between the CL center and the center of the eye's entrance pupil. A choice of different filters enabled the software operator to identify the image that provided the sharpest CL edge (Figure 1B). Due to the inherent low and varying contrast between the nasal and temporal CL edges against the white scleral background, attempts to automatically detect the CL edge were not successful. The program was therefore designed to allow manual selection of a minimum of six CL edge points and a minimum of six pupil edge points, to which best circles were fit using the least-square fitting approach (Figure 1D). Using the same camera setup, a calibration card, featuring a $15 \mathrm{~mm} \times 15 \mathrm{~mm}$ grid, was also photographed to determine the scale factor for the conversion to the real-world coordinates of the post-processed images. The horizontal $(x)$ and the vertical (y) differences between the circle centers obtained from the $\mathrm{CL}$ edge and the pupil edge were defined as the vertical and horizontal decentration of the $\mathrm{CL}$ in millimeter. Negative signs indicate temporal and inferior decentration, and positive signs indicate nasal and superior decentration. Total decentration was determined through trigonometric analysis, by calculating the square root of the sum of the squares of the horizontal and vertical decentration of each lens.

As the ratio between the CL diameter (CL Dia) and horizontal visible iris diameter (HVID) can affect CL fit ${ }^{19}$ and thus lens centration, the HVID was also measured for each participant using the same photograph and image analysis program.

\section{Instruments}

At the baseline visit, objective refraction and keratometry readings were obtained for each participant using the closed-view Auto Keratometer-Refractor Canon RK-3 (Canon Inc., Tokyo, Japan). Third-order aberrations were measured with and without study lenses on eye using the BHVI-EyeMapper (Brien Holden Vision Institute, Sydney, NSW, Australia). Details of this aberrometer instrument have been explained earlier. ${ }^{20}$ With each study lens on eye, five repeats were performed for distance (ie, +1.00D fogging) at low illumination conditions and third-order aberration coefficients were retrieved for the $4 \mathrm{~mm}$ circular and natural on-axis pupil diameter. While the constant fixed circular pupil analysis diameter of $4 \mathrm{~mm}$ allows a direct comparison of the spherical aberration terms between

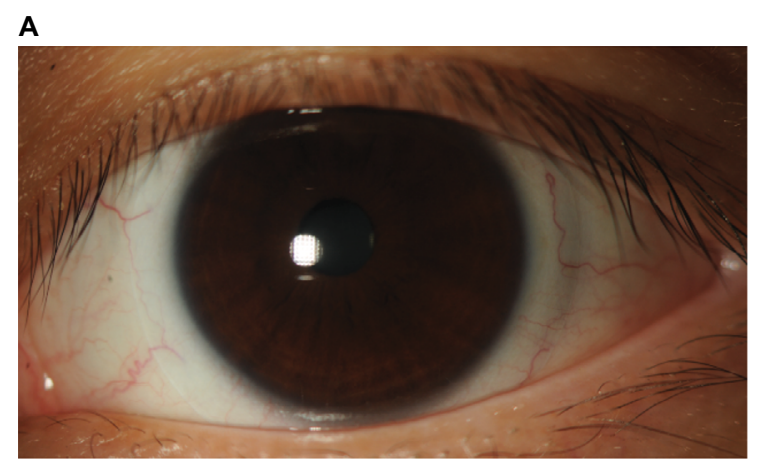

B

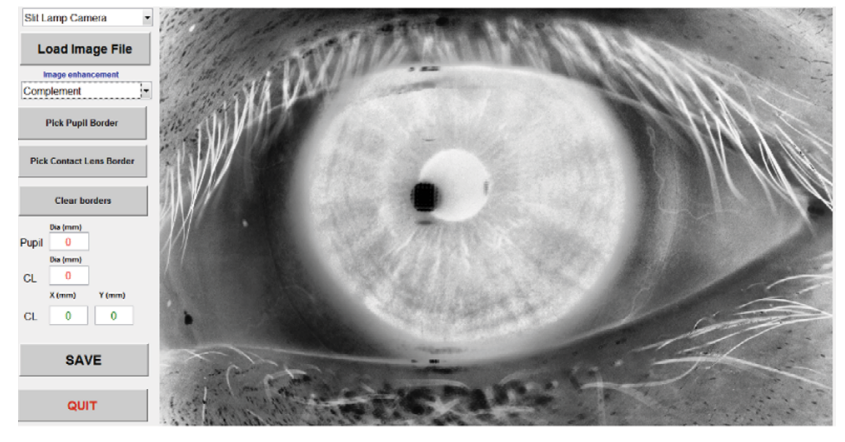

C

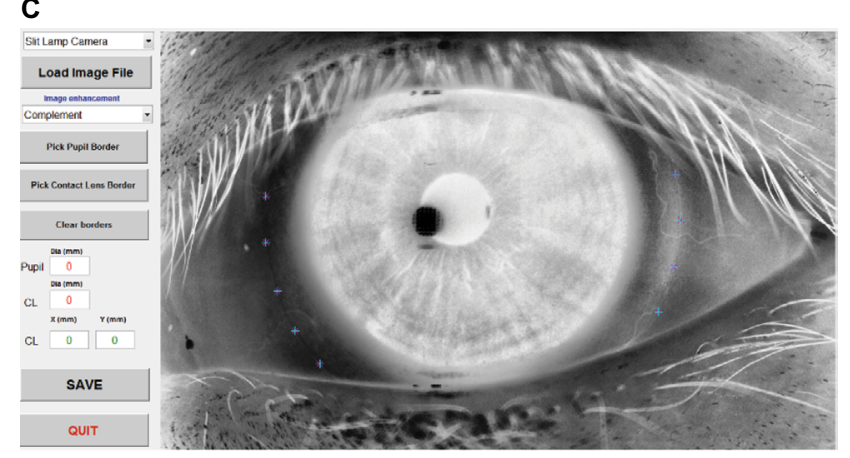

D

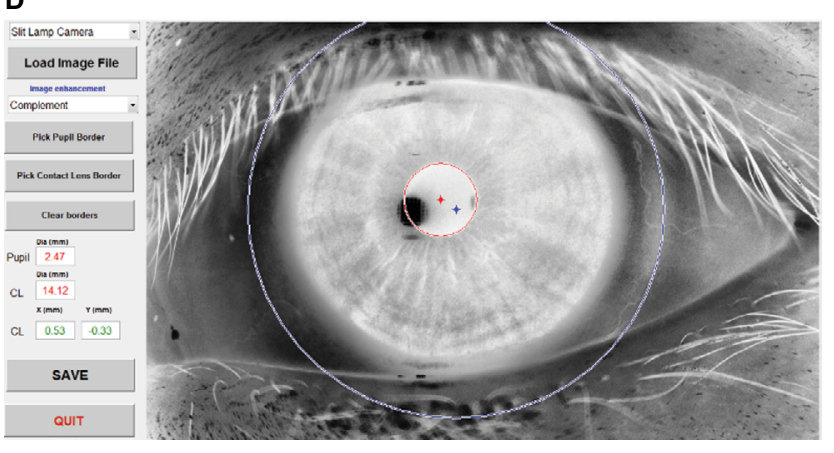

Figure I Measurement of contact lens centration.

Notes: A photograph taken on the slit-lamp camera setup with a $C L$ on eye (A). To determine $C L$ centration, the same picture was uploaded into the user interface of the dedicated $\mathrm{CL}$ centration program that enabled: I) the enhancement of the $\mathrm{CL}$ edge by applying different filters (B), 2) a manual selection of a minimum of six points at the $\mathrm{CL}$ and pupil borders (C), and 3 ) the fitting of the best circles to determine the differences ( $x$ and $y$, in millimeter) between the CL and pupil centers (D). Abbreviation: $\mathrm{CL}$, contact lens. 
lens types, the natural circular pupil diameter provides information on any associations with respect to vision.

\section{Statistical analyses}

Data are summarized as mean \pm standard deviation (SD) for variables measured on an interval scale. The ratio of corneal curvature (CC) to $\mathrm{BC}$ of the dispensed lenses and the ratio of the HVID to CL Dia were calculated to assess CL fit. CL decentration, third-order aberrations, and ratios of $\mathrm{CC} / \mathrm{BC}$ and HVID/CL Dia were compared between lens types using linear mixed models with random participant intercept and repeated visits. If the overall lens effect was significant, post hoc analysis was performed comparing each lens to the control. Post hoc comparisons were adjusted using Bonferroni correction. The association between CL decentration, subjective and objective vision parameters, and third-order aberration coefficients was assessed using Pearson's correlation. The level of statistical significance was set at 5\%. Analyses were performed using SPSS 21 (IBM Corporation, Armonk, NY, USA).

\section{Results}

A total of 17 presbyopic and eight non-presbyopic participants completed the study. The baseline details for both groups are summarized in Table 3 . There was no significant difference in the $\mathrm{CC}$ between groups. However, the nonpresbyopic group had a significantly smaller HVID and a significantly larger natural pupil diameter $(P=0.005)$ than the presbyopic group.

\section{Comparison of centration data and $\mathrm{CL}$ fitting variables between study lenses}

The mean $x, y$, and total decentration values for all lenses are shown in Table 4. On average, all lenses displayed a temporal-inferior decentration, which was independent of
Table 3 Baseline details

\begin{tabular}{lll}
\hline Baseline variables & $\begin{array}{l}\text { Presbyopic group } \\
(\mathbf{n}=17)\end{array}$ & $\begin{array}{l}\text { Non-presbyopic } \\
\text { group }(\mathbf{n = 8})\end{array}$ \\
\hline $\begin{array}{l}\text { Sex (female) } \\
\text { Ethnicity }\end{array} \quad \mathrm{n}=6(35.3 \%)$ & $\mathrm{n}=5(62.5 \%)$ \\
$\quad$ Caucasian & $\mathrm{n}=\mathrm{I} 3(76.5 \%)$ & $\mathrm{n}=2(25 \%)$ \\
$\quad$ Asian & $\mathrm{n}=2(\mathrm{II.8 \% )}$ & $\mathrm{n}=5(62.5 \%)$ \\
$\quad$ Others & $\mathrm{n}=2(\mathrm{II.8 \% )}$ & $\mathrm{n}=\mathrm{I}(\mathrm{I} .5 \%)$ \\
Neophytes & $\mathrm{n}=5(3 \mathrm{I} .3 \%)$ & $\mathrm{n}=\mathrm{I}(\mathrm{I} .5 \%)$ \\
Age (years) & $55 . \mathrm{I} \pm 6.9$ & $3 \mathrm{I} .0 \pm 3.3$ \\
Age range (years) & $45.9-68.6$ & $25.9-36.4$ \\
Spherical equivalent & $-\mathrm{I} .96 \pm 2.03$ & $-3.5 \mathrm{I} \pm \mathrm{I} .79$ \\
(subjective refraction, D) & & \\
Add power (D) & $\mathrm{I} .8 \mathrm{I} \pm 0.35$ & - \\
Natural pupil diameter & $4.62 \pm 0.89$ & $6.08 \pm 0.64$ \\
(mm, low illumination) & & \\
HVID (mm) & $\mathrm{II} .49 \pm 0.43$ & $\mathrm{II} .10 \pm 0.47$ \\
CC (mm) & $7.82 \pm 0.23$ & $7.7 \mathrm{I} \pm 0.18$ \\
\hline
\end{tabular}

Notes: Data are presented as either $\mathrm{n}(\%)$, or mean \pm SD.

Abbreviations: CC, corneal curvature; HVID, horizontal visible iris diameter; $\mathrm{SD}$, standard deviation

the group. In both groups, the Proclear ${ }^{\circledR}$ MFCL Near lens was significantly more inferiorly decentered than the control lens. In the non-presbyopic group, total decentration with the Proclear ${ }^{\circledR}$ MFCL Distance and Near lenses was significantly greater than for the control lens. The distribution of CL decentration data points, as indicated by the SD, was similar for all lenses in the presbyopic group, which showed a slightly wider distribution along the horizontal meridian than along the vertical meridian. In the non-presbyopic group, the distribution of data points for the study lenses was generally much wider when compared to the control lens and the distribution was greater along the vertical meridian.

Table 5 lists the ratio between $\mathrm{CC}$ and $\mathrm{BC}$ of the dispensed lenses and the ratio between the HVID and CL Dia. When compared to the control, both ratios were significantly smaller for both Proclear ${ }^{\circledR}$ MFCLs in both groups.

Table 4 Mean $x, y$, and total decentration \pm SD $(\mathrm{mm})$ of all study lenses

\begin{tabular}{|c|c|c|c|c|c|c|c|c|c|c|}
\hline \multirow[t]{2}{*}{ Group } & \multirow[t]{2}{*}{ Lens } & \multicolumn{3}{|c|}{$x$-Decentration } & \multicolumn{3}{|c|}{$y$-Decentration } & \multicolumn{3}{|c|}{ Total decentration } \\
\hline & & Mean & SD & $P$-value & Mean & SD & $P$-value & Mean & SD & $P$-value \\
\hline \multirow[t]{7}{*}{ Presbyopes } & AirOptix ${ }^{\circledR}$ Aqua & -0.32 & 0.30 & 0.978 & -0.09 & 0.26 & $<0.05$ & 0.46 & 0.22 & 0.528 \\
\hline & CLARITI $^{\circledR}$ I Day MFCL & -0.37 & 0.31 & & -0.12 & 0.30 & & 0.52 & 0.26 & \\
\hline & Proclear $^{\circledR}$ MFCL Distance & -0.32 & 0.32 & & -0.23 & 0.27 & & 0.53 & 0.22 & \\
\hline & Proclear $^{\circledR}$ MFCL Near & -0.36 & 0.31 & & $-0.26^{*}$ & 0.26 & & 0.55 & 0.24 & \\
\hline & ACUVUE ${ }^{\circledR}$ Bifocal & -0.36 & 0.30 & & -0.16 & 0.28 & & 0.52 & 0.24 & \\
\hline & AirOptix ${ }^{\circledR}$ MFCL & -0.35 & 0.25 & & -0.12 & 0.23 & & 0.46 & 0.19 & \\
\hline & PureVision $^{\circledR}$ MFCL & -0.36 & 0.31 & & -0.12 & 0.29 & & 0.51 & 0.24 & \\
\hline \multirow[t]{3}{*}{ Non-presbyopes } & AirOptix ${ }^{\circledR}$ Aqua & -0.33 & 0.17 & 0.613 & -0.29 & 0.24 & $<0.05$ & 0.50 & 0.17 & $<0.05$ \\
\hline & Proclear $^{\circledR}$ MFCL Distance & -0.42 & 0.27 & & $-0.69 *$ & 0.45 & & $0.86 *$ & 0.42 & \\
\hline & Proclear $^{\circledR}$ MFCL Near & -0.42 & 0.38 & & $-0.70 *$ & 0.30 & & $0.88 *$ & 0.34 & \\
\hline
\end{tabular}

Note: The symbol * indicates significant difference when compared to the control $(P<0.05)$.

Abbreviation: MFCL, multifocal soft contact lens. 
Table 5 Ratio of $C C / B C$ of the dispensed lenses and ratio of HVID/CL Dia

\begin{tabular}{|c|c|c|c|}
\hline Group & Lens & $\mathrm{CC} / \mathrm{BC}$ & $\begin{array}{l}\text { HVID/ } \\
\text { CL Dia }\end{array}$ \\
\hline \multirow[t]{7}{*}{ Presbyopes } & AirOptix ${ }^{\circledast}$ Aqua & 0.909 & 0.809 \\
\hline & CLARITI ${ }^{\circledR}$ I Day MFCL & 0.909 & $0.820 *$ \\
\hline & Proclear ${ }^{\circledR}$ MFCL Distance & $0.899 *$ & $0.804 *$ \\
\hline & Proclear ${ }^{\circledR}$ MFCL Near & $0.899 *$ & $0.799 *$ \\
\hline & ACUVUE ${ }^{\circledR}$ Bifocal & 0.919 & 0.809 \\
\hline & AirOptix ${ }^{\circledR}$ MFCL & 0.907 & 0.815 \\
\hline & PureVision ${ }^{\circledR}$ MFCL & 0.910 & $0.82 I^{*}$ \\
\hline \multirow[t]{3}{*}{ Non-presbyopes } & AirOptix ${ }^{\circledR}$ Aqua & 0.898 & 0.779 \\
\hline & Proclear ${ }^{\circledR}$ MFCL Distance & $0.888^{*}$ & $0.770^{*}$ \\
\hline & Proclear $^{\circledR}$ MFCL Near & $0.883^{*}$ & $0.775^{*}$ \\
\hline
\end{tabular}

Note: The symbol $*$ indicates significant difference when compared to the control $(P<0.05)$. Abbreviations: $\mathrm{BC}$, base curve; $\mathrm{CC}$, corneal curvature; $\mathrm{CLs}$, contact lenses; $\mathrm{CL}$ $\mathrm{Dia}$, contact lens diameter; HVID, horizontal visible iris diameter ; MFCL, multifocal soft contact lens.

For all lenses combined, a significant but weak negative correlation was found in the presbyopic group between $\mathrm{CC} /$ $\mathrm{BC}$ and $y$-decentration (Figure 2A; $r=-0.191, P<0.05$ ), but there was no correlation $(P=0.908)$ between the ratio of HVID/CL Dia and $y$-decentration. In the non-presbyopic group, ie, the group showing a greater magnitude and spread of decentration, a strong and significant correlation between HVID/CL Dia was found with $y$-decentration (Figure 2B; $r=0.550, P<0.05)$, indicating the steeper the $\mathrm{CC}$ and the smaller the HVID, the greater was $y$-decentration. There was no correlation $(P=0.269)$ between $\mathrm{CC} / \mathrm{BC}$ and $y$-decentration in the non-presbyopic group.

\section{Third-order aberrations}

Figure 3A compares the unaided and lens-induced third-order aberrations (ie, the difference of the aberrations measured with and without lens) for the different study lenses of both groups. To allow direct comparison of the different lenses, all data shown in Figure 3A were obtained for a $4 \mathrm{~mm}$ pupil analysis diameter. In both groups, lens-induced vertical coma $(C[3,-1])$ was, by at least tenfold, significantly more positive for the Proclear ${ }^{\circledR}$ MFCL Distance lens and significantly more negative for the Proclear ${ }^{\circledR}$ MFCL Near lens when compared to the control.

Figure 3B shows the third-order aberrations as measured with and without lens on eye for natural pupil sizes under low illumination condition. Due to the increased negative inherent $\mathrm{C}(3,-1)$ in the presbyopic group, the positive lens-induced $\mathrm{C}(3,-1)$ of the Proclear ${ }^{\circledR}$ MFCL Distance lens (Figure 3A) was canceled out and became close to zero (Figure 3B). Conversely, C (3, -1$)$ with lens on eye became more negative for all the other lens types in this group. As for
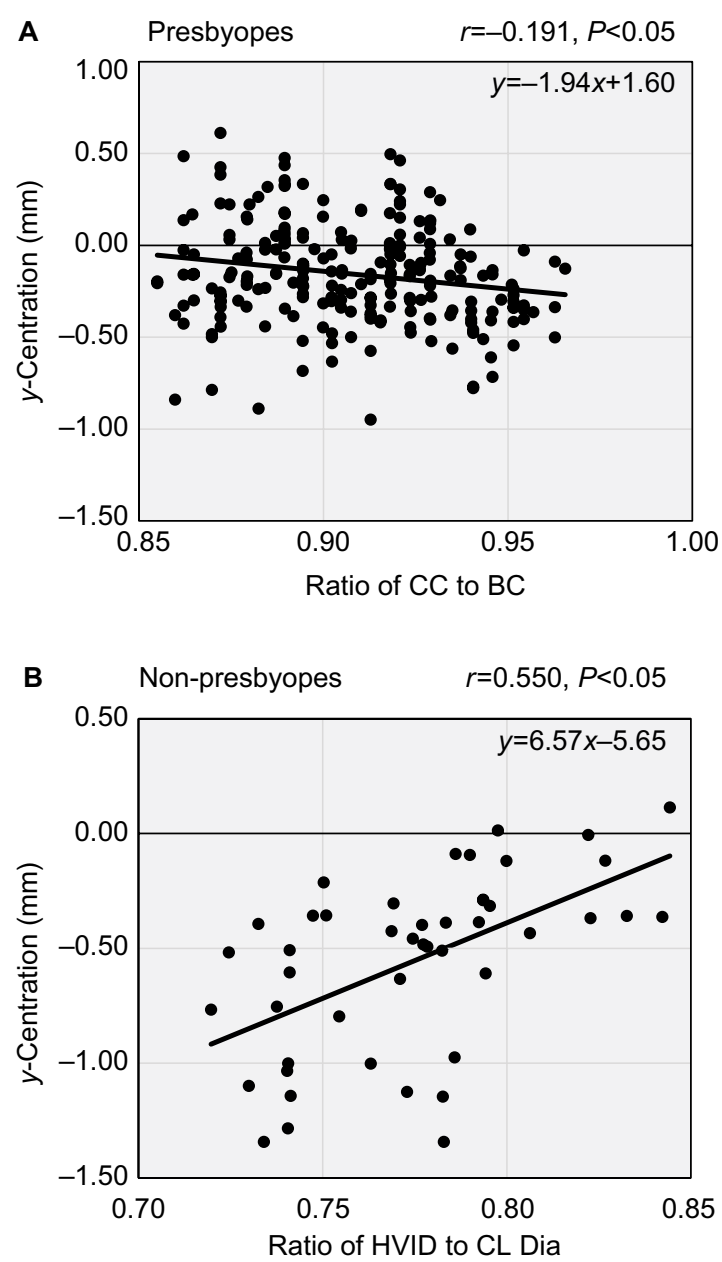

Figure 2 Correlation between the ratio of $C C / B C$ and $y$-decentration in the presbyopic group $(\mathbf{A})$ and the ratio of the HVID/CL Dia and $y$-decentration in the non-presbyopic group (B).

Abbreviations: $B C$, base curve; $C C$, corneal curvature; $C L$ Dia, contact lens diameter; HVID, horizontal visible iris diameter.

the non-presbyopic group, inherent third-order aberrations were small overall, and thus there was no significant difference between lens-induced measurements and measurements obtained with lens on eye.

\section{$\mathrm{CL}$ decentration and vision}

Figures 4-6 show the association between total decentration for the combined study lenses tested and all the visual performance variables in the presbyopic and non-presbyopic groups. Independent of the group, there was no statistically significant correlation for the HCVA with total decentration. For LCVA measurements, the only exception was in the nonpresbyopic group, which showed a decrease in LCVA when total decentration increased (Figure 4).

In the presbyopic group, the correlation of total MFCL decentration with subjective vision variables was weak (Figure 5; $r<|0.191|)$, but a significant positive correlation $(P<0.05)$ was found for the ratings on near vision (Figure $5 \mathrm{C}$ ) and vision after 

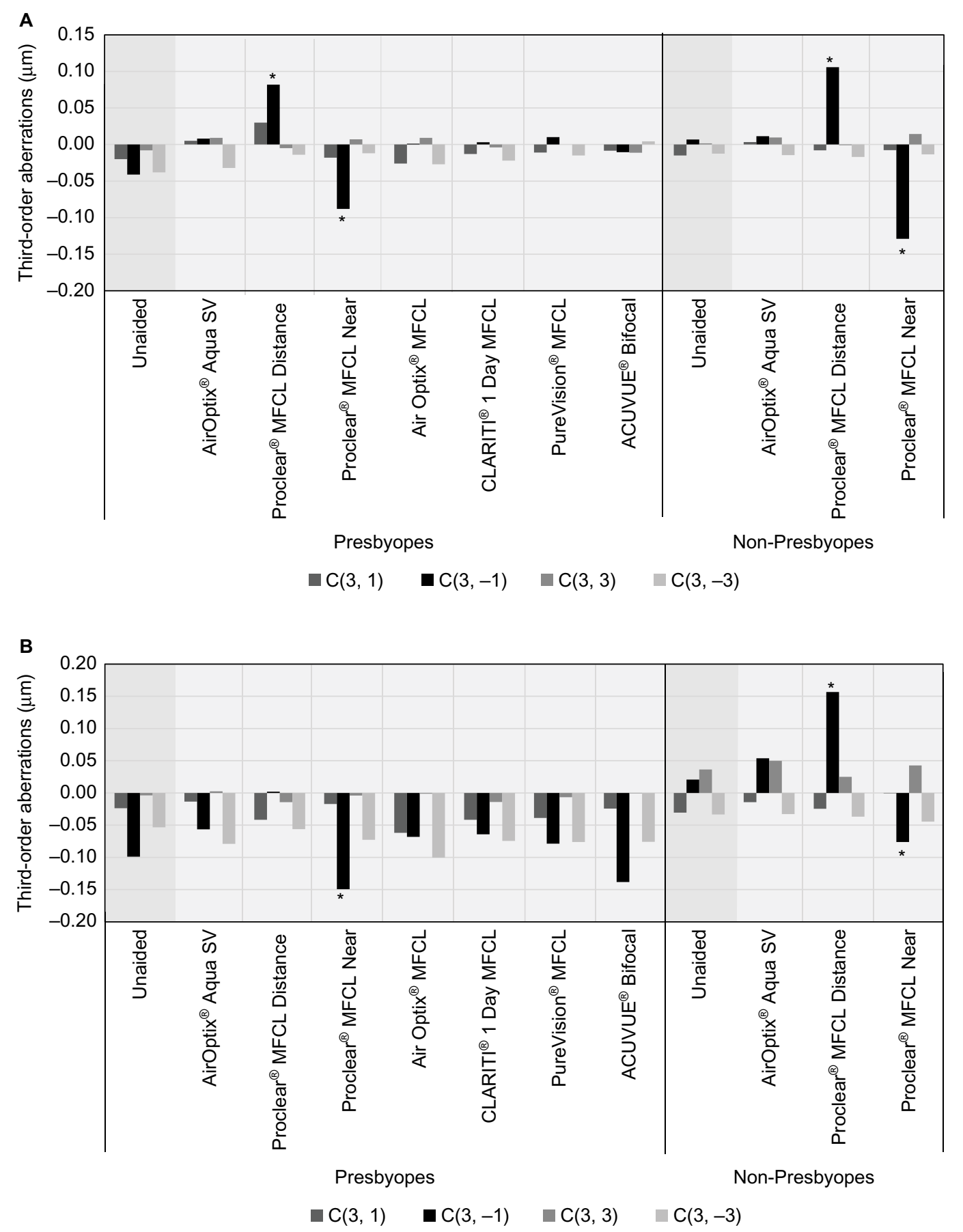

Figure 3 Third-order aberrations

Notes: (A) Unaided and lens-induced (ie, difference of aberrations measured with and without lens) third-order aberrations ( $\mu \mathrm{m}$; $4 \mathrm{~mm}$ pupil diameter) for the different study lenses. (B) Third-order aberrations measured with and without (unaided) lens on eye ( $\mu \mathrm{m}$, natural pupil diameter) for the different study lenses. $*$ indicates significant difference $(P<0.05)$ when compared to the control.

Abbreviations: MFCL, multifocal soft contact lens; SV, single vision.

a blink (Figure 5F), indicating an improvement in vision as the total decentration increased. A total MFCL decentration of $0.50 \mathrm{~mm}$, which is similar to the mean total decentration found in this presbyopic group, led to an average improvement in visual performance of these two subjective variables of 0.81 units, which can be considered a perceivable difference.
A moderate and significant negative correlation $(r \leq-0.300$, $P<0.05$ ) with total MFCL decentration was found in the nonpresbyopic group for six out of seven subjective vision variables (Figure 6A-G), where negative correlation indicates a decrease in visual performance as total decentration increases. On average, a total decentration of $0.50 \mathrm{~mm}$ led to an average 

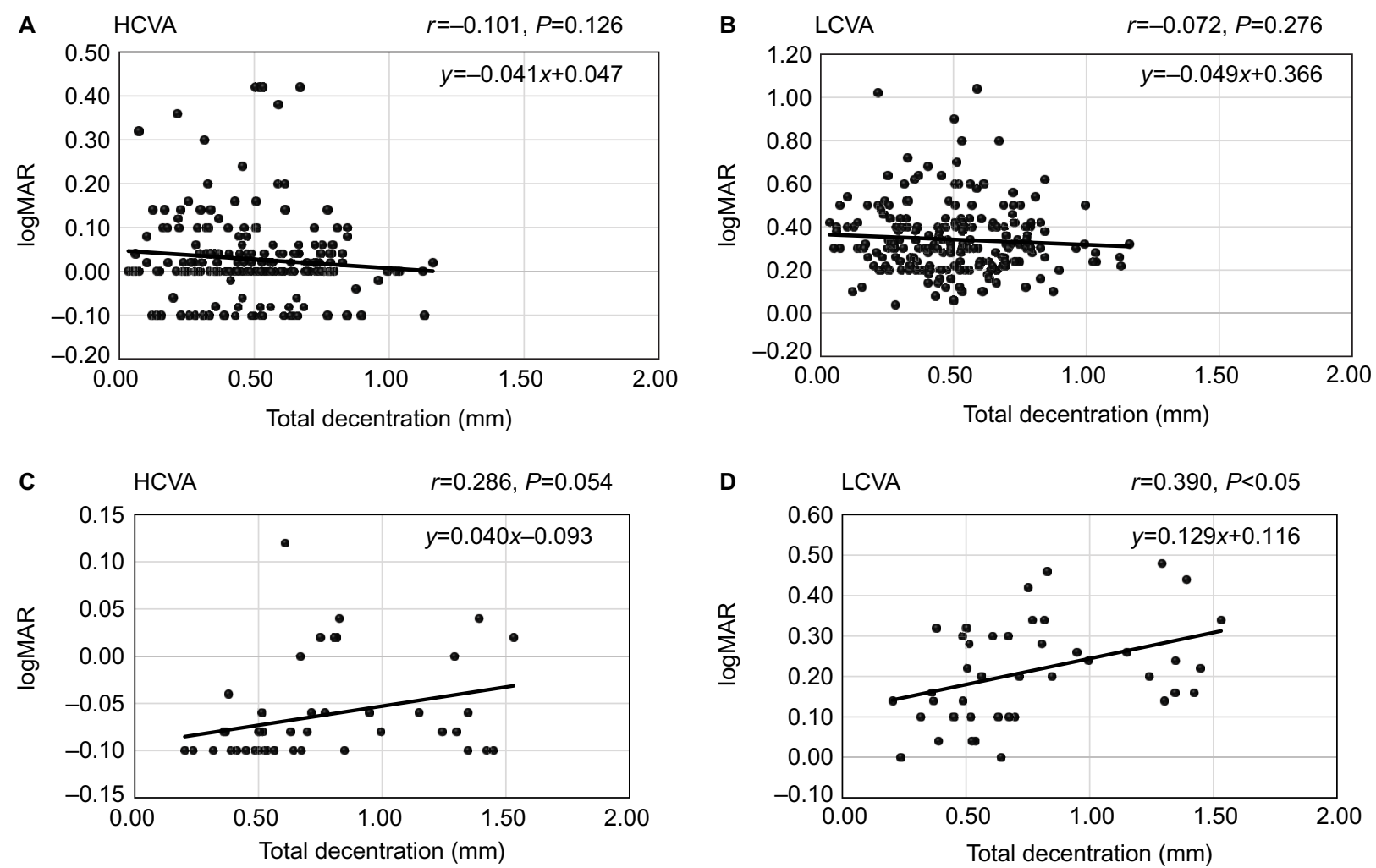

Figure 4 HCVA and LCVA as a function of total decentration in the presbyopic (A, B) and non-presbyopic (C, D) groups, respectively. Abbreviations: HCVA, high-contrast visual acuity; LCVA, low-contrast visual acuity.

reduction in visual performance (all seven subjective variables combined) of 1.45 units, which is a perceivable difference.

\section{Discussion}

\section{CL centration}

Increased decentration of Proclear ${ }^{\circledR}$ MFCL has been noticed earlier. ${ }^{11,14}$ Lens parameters such as BC and CL Dia in combination with the related ocular parameters of the individual CCs and HVIDs can provide an indication of the differences found in lens centration. ${ }^{21}$ Results from the current study showed that, independent of the group, the ratio of $\mathrm{CC} / \mathrm{BC}$ and the ratio of HVID/CL Dia of the Proclear ${ }^{\circledR}$ MFCLs were significantly smaller when compared to the control lens. This would explain the generally looser fit on eye, and thus the greater decentration with the Proclear ${ }^{\circledR}$ MFCLs in the two groups assessed in the current study. Although it is anticipated that the centration of the MFCLs could have been improved with a lens featuring a steeper BC and/or a smaller CL Dia, unlike with SV lenses for which manufacturers usually offer more than one BC and/or CL Dia, all MFCLs tested in the current study were only available in one BC and one CL Dia.

When compared to the presbyopic group, the increased decentration in the non-presbyopic group can be attributed to the smaller HVID of this group. Previous studies have shown that Asian eyes have generally smaller HVIDs than Caucasian eyes, ${ }^{22,23}$ which would explain why the non-presbyopic group in the current study comprising $62.5 \%$ of Asians had a significantly smaller mean HVID than the presbyopic group that comprised only $11.8 \%$ of Asians. Due to the limited selection available on BCs and CL Dia in MFCLs, care needs to be taken in terms of CL centration when aiming to fit certain MFCLs to a certain population group.

\section{Third-order aberrations}

To our knowledge, only a few studies ${ }^{10,11,24}$ have reported on lens-induced higher-order aberrations with commercial MFCLs. The study by Patel et $\mathrm{al}^{24}$ found a significant correlation in $\mathrm{C}(3,1)$ with and without Focus Progressive ${ }^{\circledR}$ MFCLs on eye; however, they did not assess whether possible decentration of the lenses led to the lens-induced changes. In a group of non-presbyopes, the study by Peyre et $\mathrm{al}^{10}$ assessed third, fourth, and fifth higher-order aberrations as measured after pupil dilation with eight commercial MFCLs. Three of their MFCLs, ie, Proclear ${ }^{\circledR}$ MFCL Distance, Proclear ${ }^{\circledR}$ MFCL Near, and ACUVUE ${ }^{\circledR}$ Bifocal, were also tested in the current study. In agreement with the study by Peyre et al, out of all MFCL test lenses, the two Proclear $^{\circledR}$ MFCLs induced the greatest amounts of even 

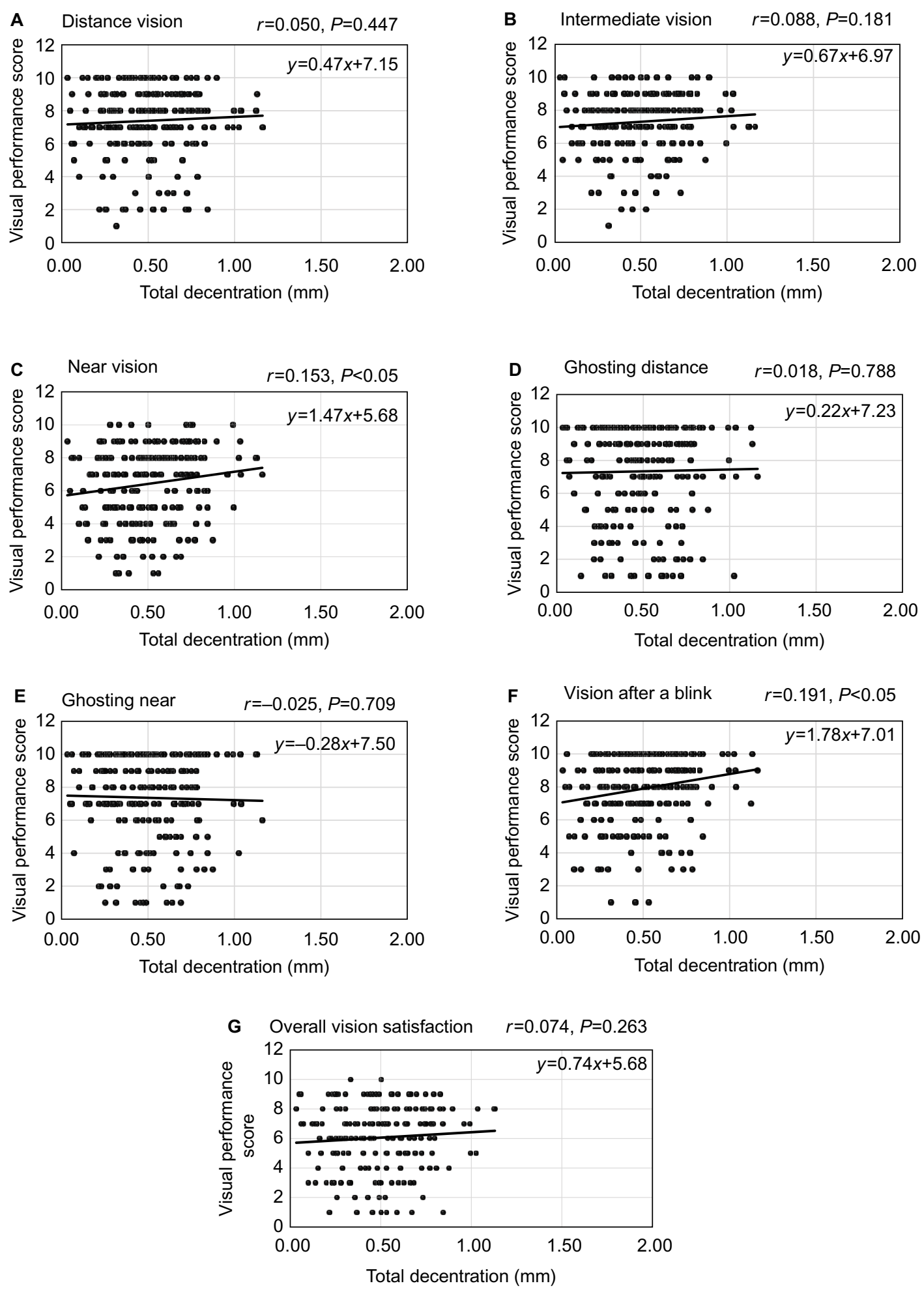

Figure 5 Subjective visual performance variables as a function of total decentration in the presbyopic group (A-G).

and odd higher-order aberrations. Although they also did not measure lens decentration, they attributed the increase in odd higher-order aberrations to the possible relative decentration of the MFCLs to the pupil. Another recent study in non-presbyopes ${ }^{11}$ measured third- and fourthhigher-order aberrations as well as lens decentration with five commercial SV and eleven commercial MFCLs on eye. Out of all MFCLs, only the Proclear ${ }^{\circledR}$ MFCLs exhibited a significant difference in $\mathrm{C}(3,-1)$ when compared to an SV control and they were also the only MFCLs that were significantly decentered, which is in agreement with the findings in both groups of the current study. 

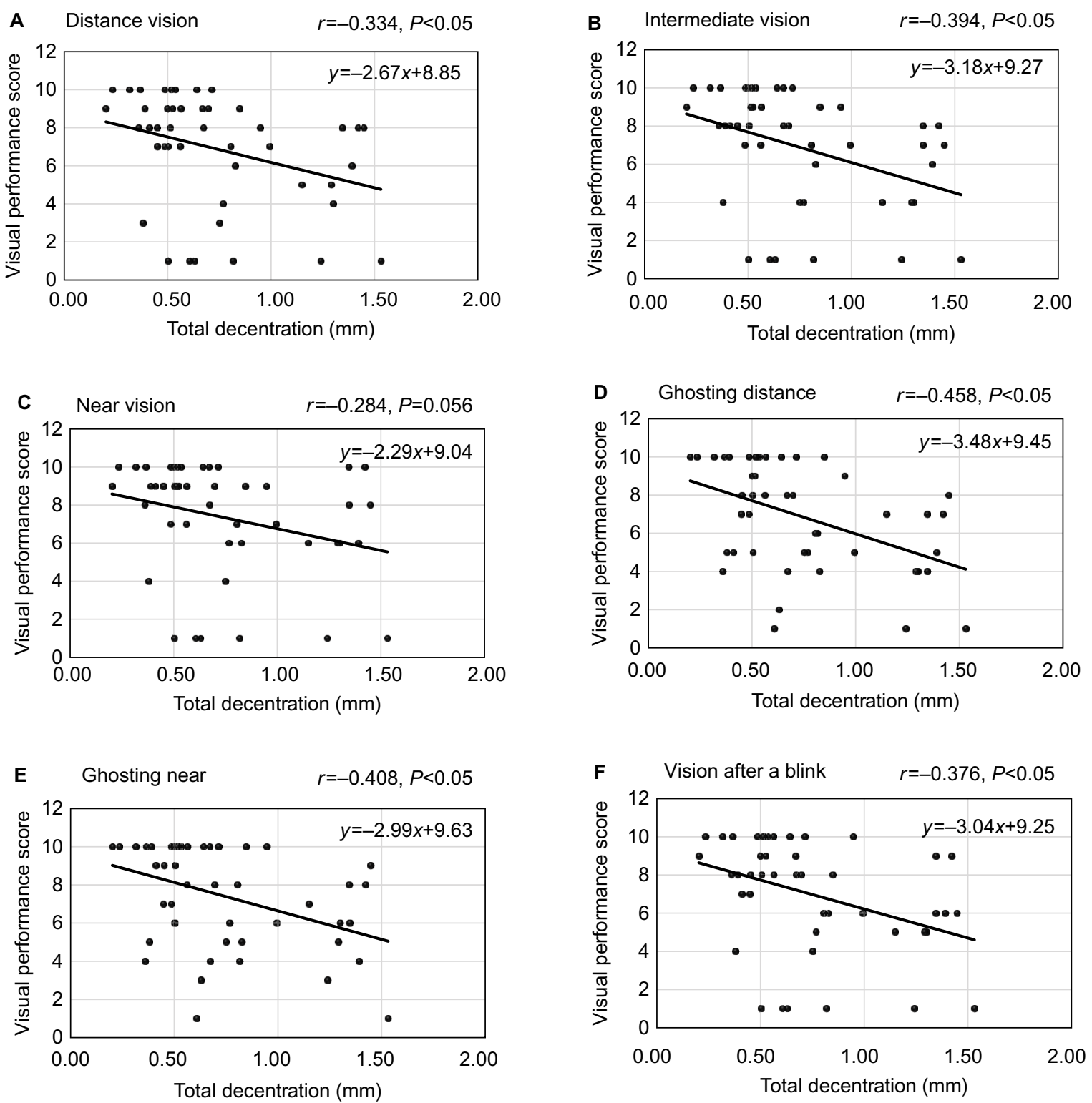

G Overall vision satisfaction $\quad r=-0.406, P<0.05$

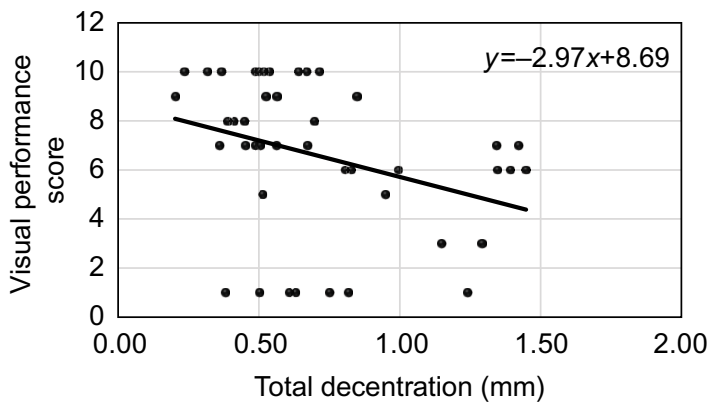

Figure 6 Subjective visual performance variables as a function of total decentration in the non-presbyopic group (A-G). 
A computational model assessing the effect of translation of an optical device on eye describes the dependency of spherical aberration with $\mathrm{C}(3,-1) \cdot{ }^{16}$ This model confirms the results with the Proclear ${ }^{\circledR}$ MFCLs in the current study, which showed that when decentered in the same direction, MFCLs with positive spherical aberration would induce $\mathrm{C}(3,-1)$ of opposite sign than MFCLS with negative spherical aberration.

In general, it should be noted that there are some methodological limitations when higher-order aberrations are measured with MFCLs on eye. Previously, it has been discussed ${ }^{11}$ that the impact of multiple refractive zones across the pupillary zone can lead to the canceling out of aberrations across the measured pupil, making a direct comparison of induced aberrations between the different MFCL types difficult. This is particularly the case for concentric bifocal lens designs, and thus the presented aberration measurements with the ACUVUE ${ }^{\circledR}$ Bifocal lens in this study need to be interpreted with caution. However, as there were no significant differences between pupil sizes for the measurements obtained with the study lenses in each group, a good indication of the direction and magnitude on the average lens-induced thirdorder aberrations for the group-specific pupil size is given. Although, it would also have been of interest to assess the impact of certain third-order aberration coefficients, such as $\mathrm{C}(3,-1)$, on vision, such an analysis was not performed due to the different illumination measurement conditions, ie, aberration measurements were conducted under low illumination conditions and visual performance was assessed under mesopic pupil conditions.

\section{Multifocal $\mathrm{CL}$ decentration and vision}

The current study aimed to assess the association between MFCL decentration, HCVA and LCVA, and subjective vision variables in presbyopes and non-presbyopes. A perceivable and statistically significant association was found for most vision variables in the non-presbyopic group, but not in the presbyopic group. Primarily, the difference between groups can be attributed to the greater magnitude of total decentration and the larger natural pupil diameters in the non-presbyopic group, leading to an increase in aberrations when compared to the presbyopic group. Further, it should be noted that the sample size and number of lenses tested in the non-presbyopic group were lower, which limits the direct comparison of group results. The study by Fernández-Sánchez et a ${ }^{17}$ assessed the impact of lens-induced third-order aberrations (coma: $0.05 \mu \mathrm{m}, 0.13 \mu \mathrm{m}$, and $1.03 \mu \mathrm{m}$; trefoil: $0.07 \mu \mathrm{m}, 0.17 \mu \mathrm{m}$, and $0.96 \mu \mathrm{m})$ on objective vision in the non-presbyopic group and they found that only the large values $(\sim 1 \mu \mathrm{m})$ of coma and trefoil induced with purpose-designed soft CLs significantly reduced HCVA and LCVA. In the current study, it was shown that significantly decentered commercial MFCLs (Proclear ${ }^{\circledR}$ MFCLs) induced third-order aberrations of $|0.08|-|0.13| \mu \mathrm{m}$ (4 mm pupil analysis diameter). These values are much lower than the values which showed a significant change in HCVA and LCVA in the study by Fernández-Sánchez et al; ${ }^{17}$ nevertheless it was shown that there was an association between increased MFCL decentration and a reduction in LCVA, eg, total MFCL decentration of $0.75 \mathrm{~mm}$ reduced LCVA by $0.10 \log$ MAR in the nonpresbyopic group.

Surprisingly, in the presbyopic group, a significant improvement was found in the subjective responses given for near vision and vision after a blink as the total decentration increased. There are a few possible explanations why decentration did not lead to a decrease in visual performance, as it did in the non-presbyopic group, and why the association between MFCL decentration and vision was generally lower in the presbyopic group. First, the threshold of sensation to blur during aging is raised, which implies that more change is required to become aware of a change. It could be speculated that the presbyopic group may therefore be generally less sensitive to lens decentration. Second, in agreement with previous studies, ${ }^{25-27}$ it was shown that the presbyopic group in the current study presented with increased levels of inherent third-order aberrations, which could have already decreased their distance-corrected image quality. ${ }^{27}$ With lens on eye, the magnitude of third-order aberrations was similar or even reduced for the majority of test lenses when compared to the magnitude of inherent third-order aberrations. This could explain why the association between lens-induced third-order aberrations, and thus decentration, and vision was small. Further, the two visual performance variables that showed a significant improvement with increase in total decentration were dynamic measures, ie, vision after a blink and near vision clarity (looking downwards). It could be speculated that a combination of lens decentration and an additional lens movement caused by performing those dynamic visual tasks could have led to this improvement in the ratings. Finally, it should be noted that this study was set out to assess only third-order aberrations. However, it is possible that a combination of other inherent and/or lensinduced higher-order aberrations could have also led to a change in visual performance. 


\section{Conclusion}

Certain MFCLs decentered more than others, which can primarily be attributed to differences in lens design and fitting parameters. The same lens designs also induced significant amounts of third-order aberrations. An association between MFCL decentration and seven out of nine vision variables was found in the non-presbyopic group, ie, the group where lenses were most decentered, which had larger pupils and lower levels of inherent third-order aberrations.

\section{Acknowledgments}

This work was carried out at the clinics and laboratories of the Brien Holden Vision Institute, Sydney, Australia. The research was fully funded by the Brien Holden Vision Institute. The authors would like to acknowledge the clinical team (Ms Robertson, Ms Crompton, Ms Bishop, Ms Chung, Ms Sha, Ms Diec, Ms Xu, and Mr Ozkan) and the database management team (Doctor Naduvilath and Ms Laarakkers) for their invaluable support to run the study at the Clinical Trial Centre, Brien Holden Vision Institute. The authors would also like to extend their thanks to Doctor Flanagan for reviewing the manuscript. Part of the work reported in this article was presented at the American Academy of Optometry, New Orleans, LA, USA, October 9, 2015.

\section{Disclosure}

The Brien Holden Vision Institute receives royalties from the sale of lotrafilcon B MFCL N lenses. The authors report no other conflicts of interest in this work.

\section{References}

1. Walline JJ, Greiner KL, McVey ME, Jones-Jordan LA. Multifocal contact lens myopia control. Optom Vis Sci. 2013;90(11):1207-1214.

2. Kollbaum PS, Jansen ME, Tan J, Meyer DM, Rickert ME. Vision performance with a contact lens designed to slow myopia progression. Optom Vis Sci. 2013;90(3):205-214.

3. Wallman J, Winawer J. Homeostasis of eye growth and the question of myopia. Neuron. 2004;43(4):447-468.

4. Sankaridurg P, Holden B, Smith E 3rd, et al. Decrease in rate of myopia progression with a contact lens designed to reduce relative peripheral hyperopia: one-year results. Invest Ophthalmol Vis Sci. 2011;52(13): 9362-9367.

5. Kollbaum PS, Dietmeier BM, Jansen ME, Rickert ME. Quantification of ghosting produced with presbyopic contact lens correction. Eye Contact Lens. 2012;38(4):252-259.

6. Madrid-Costa D, Garcia-Lázaro S, Albarrán-Diego C, Ferrer-Blasco T, Montés-Micó R. Visual performance of two simultaneous vision multifocal contact lenses. Ophthalmic Physiol Opt. 2013;33(1): $51-56$.
7. Papas EB, Decenzo-Verbeten T, Fonn D, et al. Utility of short-term evaluation of presbyopic contact lens performance. Eye Contact Lens. 2009;35(3):144-148.

8. Fisher K, Bauman E, Schwallie J. Evaluation of two new soft contact lenses for correction of presbyopia: the focus progressives multifocal and the Acuvue bifocal. Int Contact Lens Clin. 2000;26(4):92-103.

9. Fernandes PR, Neves HI, Lopes-Ferreira DP, Jorge JM, GonzálezMeijome JM. Adaptation to multifocal and monovision contact lens correction. Optom Vis Sci. 2013;90(3):228-235.

10. Peyre C, Fumery L, Gatinel D. Comparaison des aberrations optiques oculaires d'ordre eleve induites par differentes geometries de lentilles multifocales. [Comparison of high-order optical aberrations induced by different multifocal contact lens geometries]. J Fr Ophtalmol. 2005;28(6):599-604.

11. Fedtke C, Bakaraju RC, Ehrmann K, Chung J, Thomas V, Holden BA. Visual performance of single vision and multifocal contact lenses in non-presbyopic myopic eyes. Cont Lens Anterior Eye. 2016;39(1): 38-46.

12. Fedtke C, Ehrmann K, Thomas V, Bakaraju RC. Visual performance with multifocal soft contact lenses in non-presbyopic myopic eyes during an adaptation period. Clin Optom. 2016;8:37-46.

13. Bakaraju RC, Ehrmann K, Ho A, Papas E. Inherent ocular spherical aberration and multifocal contact lens optical performance. Optom Vis Sci. 2010;87(12):1009-1022.

14. Bakaraju RC, Fedtke C, Ehrmann K, Ho A. Comparing the relative peripheral refraction effect of single vision and multifocal contact lenses measured using an autorefractor and an aberrometer: a pilot study. J Optom. 2015;8(3):206-218.

15. Charman WN, Walsh G. Retinal image quality with different designs of bifocal contact lens. $J$ BCLA. 1986;9:13-19

16. Guirao A, Williams DR, Cox IG. Effect of rotation and translation on the expected benefit of an ideal method to correct the eye's higher-order aberrations. J Opt Soc Am A Opt Image Sci Vis. 2001;18(5):1003-1015.

17. Fernández-Sánchez V, Ponce ME, Lara F, Montés-Micó R, CastejónMochón JF, López-Gil N. Effect of 3rd-order aberrations on human vision. J Cataract Refract Surg. 2008;34(8):1339-1344.

18. Tilia D, Lazon de la Jara P, Peng N, Papas EB, Holden BA. Effect of lens and solution choice on the comfort of contact lens wearers. Optom Vis Sci. 2013;90(5):411-418.

19. Caroline PJ, Andre MP. The effect of corneal diameter on soft lens fitting, part 1. Cont Lens Spectr. 2002;17(4):56.

20. Fedtke C, Ehrmann K, Falk D, Bakaraju RC, Holden BA. The BHVIEyeMapper: peripheral refraction and aberration profiles. Optom Vis Sci. 2014;91(10):1199-1207.

21. van der Worp E, Schweizer H, Lampa M, van Beusekom M, Andre MP. The future of soft contact lens fitting starts here. Cont Lens Spectr. 2014;29:33, 34, 36-38.

22. Matsuda LM, Woldorff CL, Kame RT, Hayashida JK. Clinical comparison of corneal diameter and curvature in Asian eyes with those of Caucasian eyes. Optom Vis Sci. 1992;69(1):51-54.

23. Lam CSY, Loran DFC. Designing contact lenses for oriental eyes. $\mathrm{J} \mathrm{Br}$ Cont Lens Assoc. 1991;14(3):109-114.

24. Patel S, Fakhry M, Alió JL. Objective assessment of aberrations induced by multifocal contact lenses in vivo. CLAO J. 2002;28(4):196-201.

25. Fujikado T, Kuroda T, Ninomiya S, et al. Age-related changes in ocular and corneal aberrations. Am J Ophthalmol. 2004;138(1):143-146.

26. Wang L, Koch DD. Ocular higher-order aberrations in individuals screened for refractive surgery. J Cataract Refract Surg. 2003; 29(10):1896-1903.

27. McLellan JS, Marcos S, Burns SA. Age-related changes in monochromatic wave aberrations of the human eye. Invest Ophthalmol Vis Sci. 2001; 42(6):1390-1395. 
Clinical Optometry is an international, peer-reviewed, open access journal publishing original research, basic science, clinical and epidemiologica studies, reviews and evaluations on clinical optometry. All aspects of patient care are addressed within the journal as well as the practice of optometry including economic and business analyses. Basic and clinica

Submit your manuscript here: https://www.dovepress.com/clinical-optometry-journal research papers are published that cover all aspects of optics, refraction and its application to the theory and practice of optometry. The manuscript management system is completely online and includes a very quick and fair peer-review system, which is all easy to use. Visit http://www.dovepress. com/testimonials.php to read real quotes from published authors. 